\title{
Geomagnetic fluctuations during the 1999 Chi-Chi earthquake in Taiwan
}

\author{
Horng-Yuan Yen ${ }^{1}$, Chieh-Hung Chen ${ }^{1}$, Yih-Hsiung Yeh $^{3}$, Jann-Yeng Liu ${ }^{2}$, Chin-Ren Lin ${ }^{3}$, and Yi-Ben Tsai ${ }^{1}$ \\ ${ }^{1}$ Institute of Geophysics, National Central University, Chung-Li, Taiwan, ROC \\ ${ }^{2}$ Institute of Space Science, National Central University, Chung-Li, Taiwan, ROC \\ ${ }^{3}$ Institute of Earth Sciences, Academia Sinica, Taipei, Taiwan, ROC
}

(Received December 5, 2002; Revised December 23, 2003; Accepted December 26, 2003)

\begin{abstract}
On 21 September 1999 (Taiwan local time), a major earthquake measuring M7.3 occurred near the town of Chi-Chi in central Taiwan. After the Chi-Chi earthquake, geomagnetic data recorded by a network of 8 stations equipped with continuous recording systems was analyzed. The results revealed that the total geomagnetic intensity of the Liyutan station, about 8 kilometers from the northern end of the Chelungpu fault (considered to be related to the earthquake), fluctuated significantly for more than a month prior to the earthquake. The fluctuation features continued and then stopped after the Chia-Yi earthquake (M6.2) occurred near the southern end of the Chelungpu fault on 22 October 1999. The variation of intensity reached $200 \mathrm{nTs}$. Geomagnetic fluctuations were also found at the Tsengwen station, located about 42 kilometers from the southern end of the Chelungpu fault and 30 kilometers from the Chia-Yi earthquake. These geomagnetic disruptions with highly anomalous amplitudes associated with the Chi-Chi and Chia-Yi earthquakes appear to have been the result of the accumulation and release of crustal stress that led to the subsequently severe surface rupture at the time of the earthquakes.
\end{abstract}

Key words: Geomagnetic fluctuations, Chi-Chi earthquake, crustal stress.

\section{Introduction}

Taiwan has experienced many disastrous earthquakes in the past and can expect more in the future. Therefore, the study of earthquake prediction to lessen or, at least better anticipate an earthquake hazard has become a more important research topic in Taiwan.

Change in the magnetic field observed on the earth's surface at the time of an earthquake's occurrence is widely accepted. Many examples of geomagnetic changes associated with earthquakes have been reported (e.g., Yamazaki and Rikitake, 1970; Smith and Johnston, 1976; Honkura, 1985). In China, according to Zhu (1976), 15 months prior to the 1975 Haicheng earthquake (M7.3), geomagnetic change at Luda showed an anomalous variation (compared with that at Beijing) of more than 20 nTs. Oike (1978) and Noritomi (1978) reported that the total geomagnetic force began to increase at Beijing three months prior to the 1976 Tangshan earthquake (M7.8), reaching a maximum of $7 \mathrm{nTs}$. The ULF (Ultra-low-frequency) magnetic field signature has also been recognized as a precursor to earthquakes, such as Loma Prieta (Fraser-Smith et al., 1990) and Guam (Hayakawa et al., 1996). ULF emission data at Lunping (as a reference station of geomagnetic network of Taiwan, about $130 \mathrm{~km}$ away from the epicenter of the Chi-Chi earthquake) has recently been viewed as a convincing precursory signature for the Chi-Chi earthquake (Akinaga et al., 2001).

In Taiwan, fluctuation in the geomagnetic field associated with change in tectonic stress is identified as one facet of the earthquake prediction research program. Thus, an island-

Copy right(c) The Society of Geomagnetism and Earth, Planetary and Space Science (SGEPSS); The Seismological Society of Japan; The Volcanological Society of Japan; The Geodetic Society of Japan; The Japanese Society for Planetary Sciences; TERRAPUB. wide geomagnetic network of eight stations equipped with continuous recording systems was completed in 1988 by the Institute of Earth Sciences, Academia Sinica (Fig. 1).

At 1:47 local time, 21 September (20 September 17:47 UT), 1999, Taiwan's largest earthquake of the 20th century struck the center of the island near the small town of ChiChi. In this earthquake, about 2500 lives were lost and thousands of buildings were destroyed. The mechanism of the earthquake was a thrust fault with a strike of $\mathrm{N} 5^{\circ} \mathrm{E}$ and a dip of $34^{\circ}$ (Chang et al., 2000). The Chi-Chi earthquake triggered the Chelungpu fault (Fig. 1), some $90 \mathrm{~km}$ long, north-south trending, and mostly of the thrust type. The fault trace bent toward the northeast at its northern tip where the largest surface rupture was measured to be about $5.6 \mathrm{~m}$ horizontally and $9.8 \mathrm{~m}$ vertically (Central Geological Survey, 1999).

After the Chi-Chi earthquake, the data recorded at the stations of the geomagnetic network were examined. Clear fluctuations in geomagnetic intensity were shown at the Liyutan station and also at the Tsengwen station. This paper will focus on the fluctuations associated possibly with the Chi-Chi and Chia-Yi earthquakes.

\section{Instrumentation}

An earthquake prediction research program in Taiwan was started in 1979 via a joint effort between the Institute of Earth Sciences, Academia Sinica and the University of Southern California, funded by the National Science Council, R.O.C. and the U.S. Geological Survey (Tsai et al., 1983). Detecting local geomagnetic changes associated with earthquakes was a part of this program. A network of 24 geomagnetic stations has been in operation since 1979. Twenty-two of these stations were occupied periodically with a portable magne- 


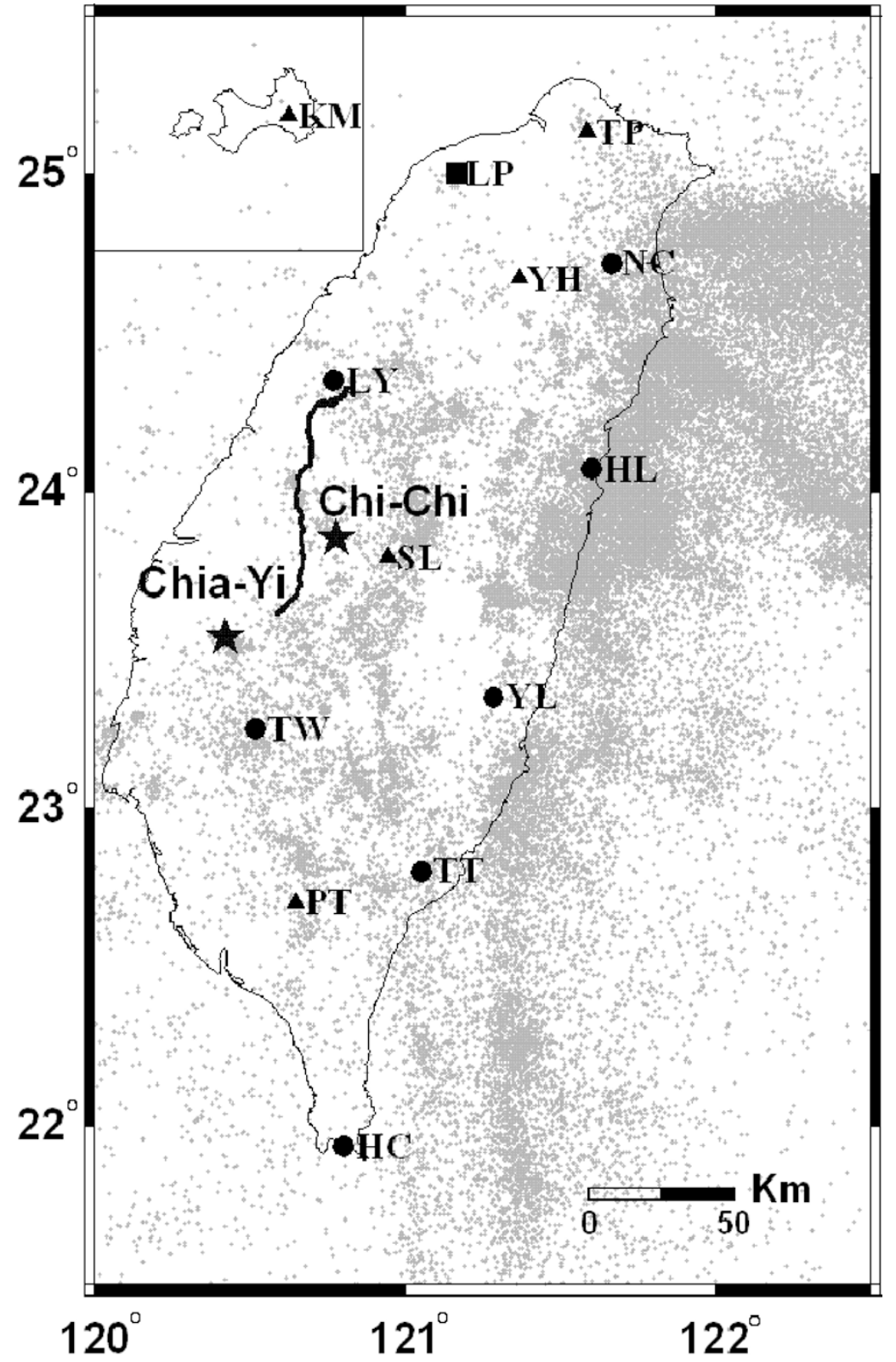

Fig. 1. The locations of the geomagnetic stations (see Table 1 for station locations) are denoted by solid squares (old reference station), solid circles (renovated the existing network stations), and solid triangles (new network stations) on the seismicity background, where events with magnitudes greater than 3.0 were recorded by the Central Weather Bureau Seismic Network in Taiwan. All stations are located in seismically active areas except for the Lunping (LP) station that is considered to be a reference station. Solid stars denote the epicenters of the Chi-Chi and Chia-Yi earthquakes. The line in central Taiwan indicates the extent of the surface rupture along the Chelungpu fault.

tometer, while two stations served as reference stations and were equipped with continuous recording systems (Yeh et al., 1981). Each geomagnetic station was chosen after careful inspection of the surrounding area and detailed surveys of the actual magnetic field nearby.

Basically, the station sites selected were far away from populated areas, all visible iron objects and power lines to avoid unwanted or manmade "noises" and interference. To make sure that there were no hidden geomagnetic disturbances close to the station site, a survey of the background geomagnetic field was undertaken at each station. During the background survey, two portable magnetometers were used. One was fixed at the prospective station; the other was moved from point to point around the prospective station out to a ra- dial distance of about 20 meters. Measurements were taken simultaneously several times at each prospective station. If the geomagnetic field did not show a significant disturbance, then the station site was accepted.

Due to manpower constraints and upgrades to a more advanced recording system, 6 of the 22 repeated stations were also equipped with continuous recording systems in 1988. This formed an island-wide geomagnetic network with 8 continuous recording stations (Fig. 1). A proton precession magnetometer (Geometrics Model G-856) with a 0.1 nT sensitivity and continuous recording system was used at each station. All stations were located in areas of high seismicity or crustal activity, except for the Lunping (LP) station. The LP station is located in a seismically quiet area in north- 

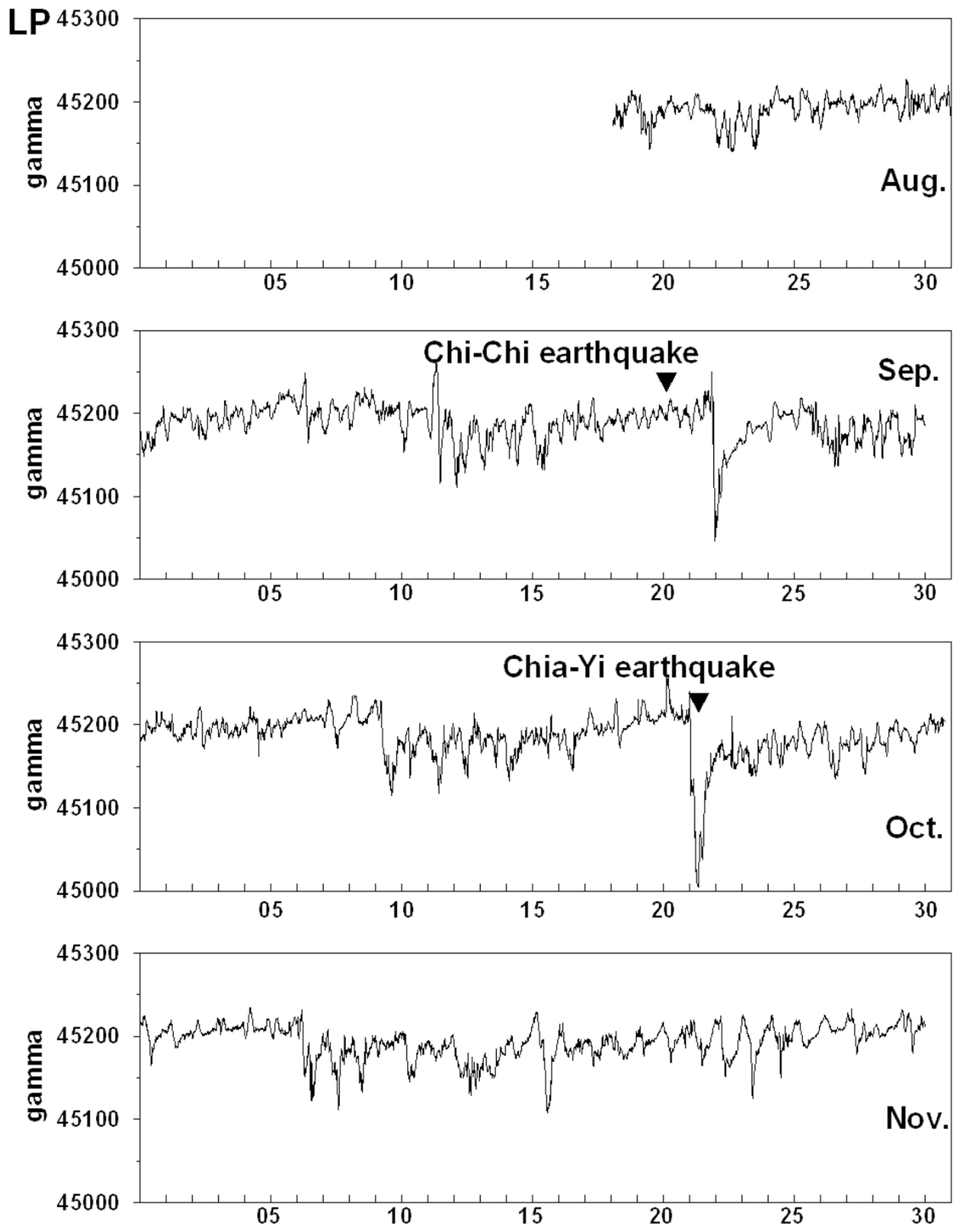

Fig. 2. Geomagnetic total intensity data recorded at the reference station (LP) from August to November 1999. No disturbance was observed before or after the Chi-Chi and Chia-Yi earthquakes, except for the two magnetic storms caused by an external source.

ern Taiwan and is considered to be a reference station. In other words, we assume that there is no stress factor to affect the geomagnetic intensity at the reference station. The Liyutan (LY) and the Tsengwen (TW) stations are located in western Taiwan. The other five stations, Neicheng (NC), Hualien (HL), Yuli (YL), Taitung (TT) and Hengchun (HC), are distributed over eastern and southern Taiwan. The sampling rate at the LP station is at 5-minute intervals, while the other stations have 10-minute intervals. We visit the stations routinely every two months to collect data and maintain instruments.

\section{Observation and Interpretation}

Following the Chi-Chi earthquake, we visited all geomagnetic stations to collect data from each station except that of the TW station where malfunctions occurred and repairs were later made.

Figure 2 shows the total geomagnetic intensity at the reference station (LP) between mid-August and November 1999. Two magnetic storms were observed about two days after the Chi-Chi earthquake and almost at the time of occurrence of the Chia-Yi earthquake, respectively. The LP station is located about 130 kilometers from the epicenter of the Chi-Chi 

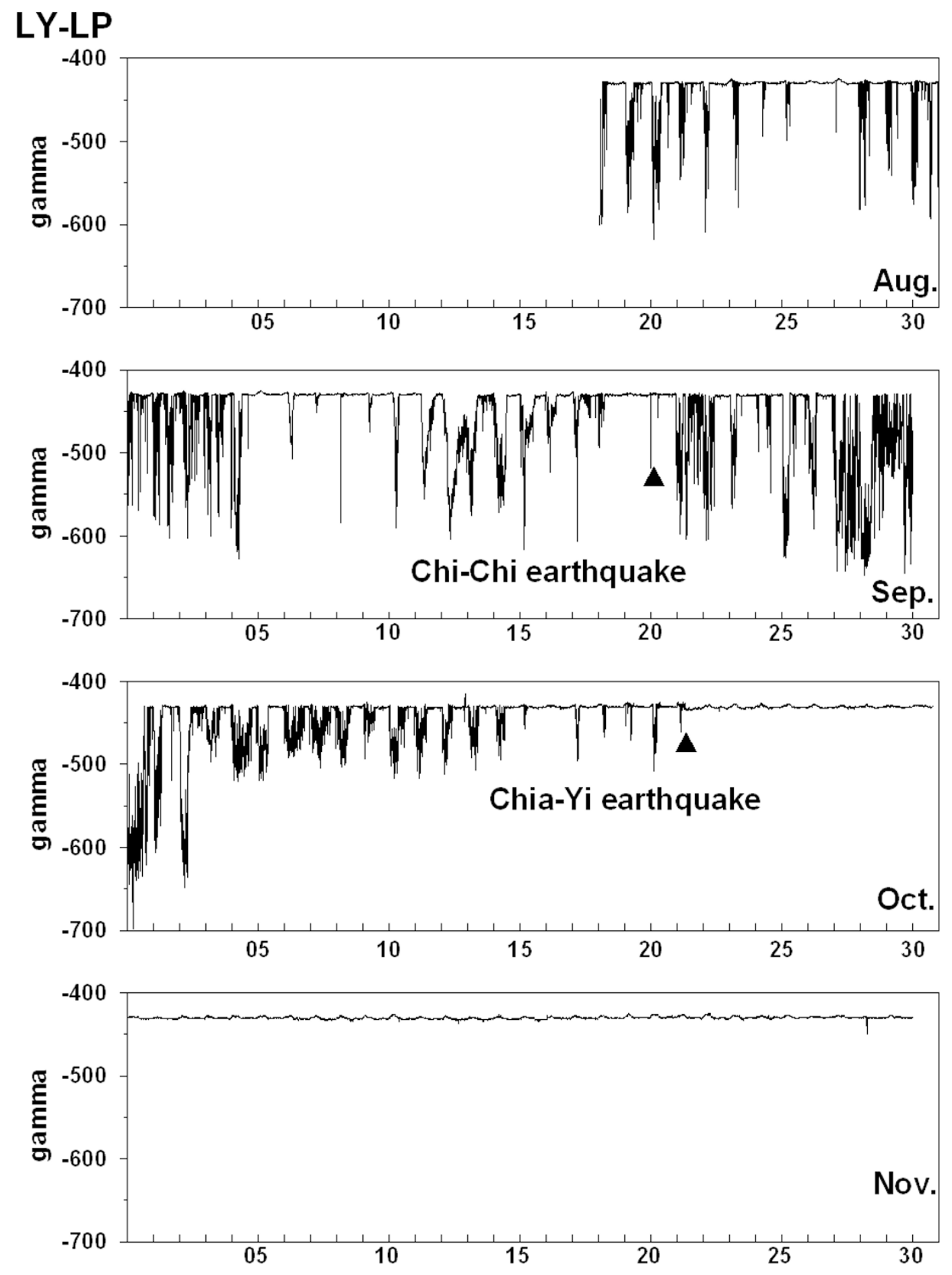

Fig. 3. Differences in geomagnetic total intensity between the Liyutan station (LY) and the reference station (LP) stations were plotted. Geomagnetic fluctuations were clearly revealed. The largest amplitude was 200 nTs. Decreasing signals of amplitudes and disturbances continued after the Chi-Chi earthquake. Following the Chia-Yi earthquake, geomagnetic fluctuations disappeared.

earthquake and 185 kilometers from the Chia-Yi earthquake. Comparing the total geomagnetic intensity shown in Fig. 2 with those of the routine observations (Yeh et al., 1981), no anomaly was revealed except for these two storms. These storms were apparently due to an external source which was strongly affected by the solar wind. Thus, it may be concluded that the total geomagnetic intensity at the reference station (LP) did not show a disturbance at the time of either the Chi-Chi earthquake or the Chia-Yi earthquake since the station is too far away from the earthquakes.

In order to detect changes in the geomagnetic field associated with tectonic stress, it is necessary to eliminate the changes originating from external sources in the observed data. A simple way to do this is to use differences of geomagnetic data between field stations and the reference station as demonstrated in Yeh et al. (1981). The Liyutan station (LY) is located about 8 kilometers from the northern end of the Chelungpu fault. At its northern end, the fault curves 


\section{TW-LP}
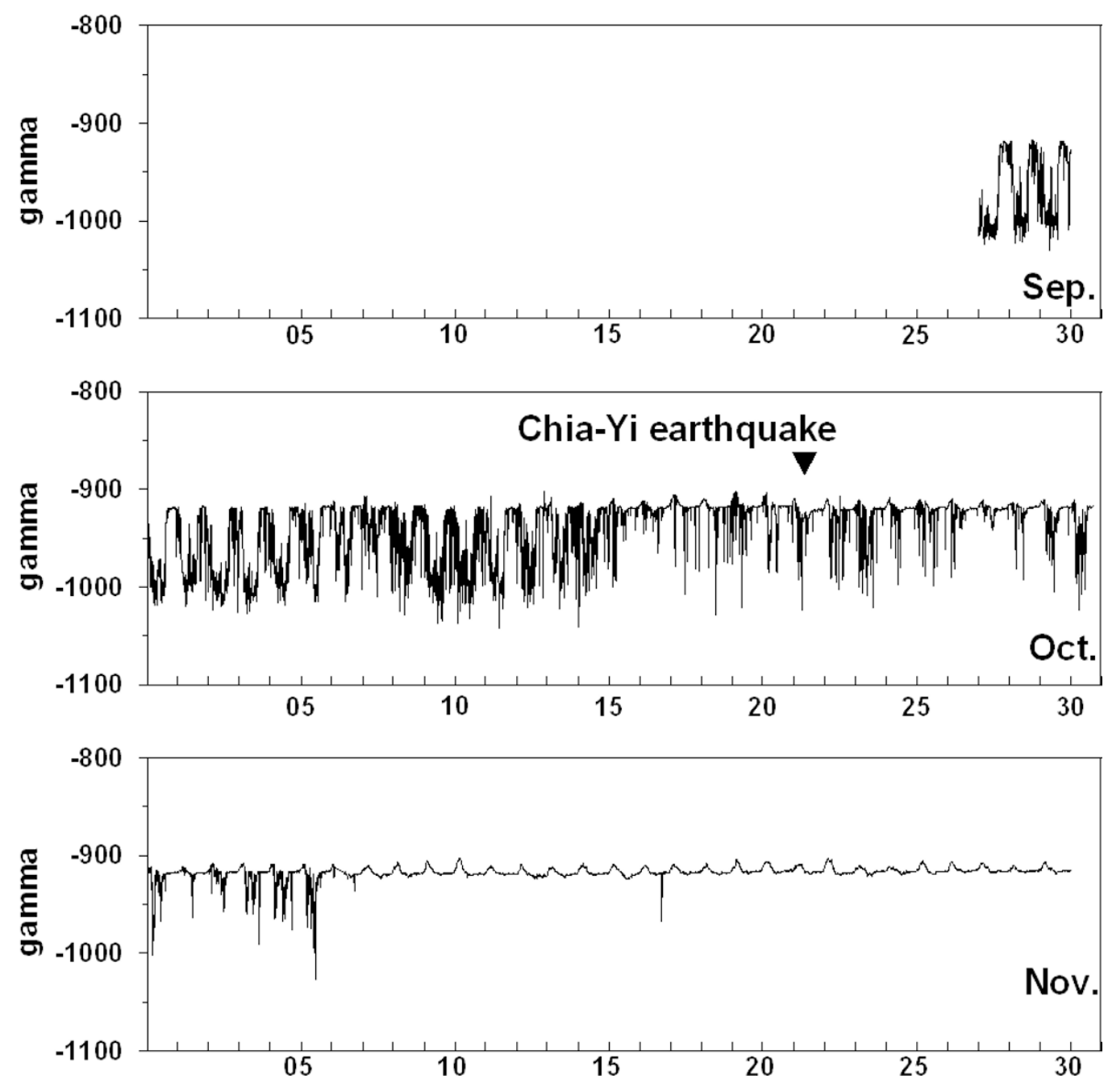

Fig. 4. Differences in geomagnetic total intensity between the Tsengwen (TW) and the Lunping (LP) stations were plotted. Geomagnetic fluctuations were also revealed. The amplitude of these disturbances was smaller than those recorded at the Liyutan (LY) station. Signals of geomagnetic disturbance recorded at the TW station continued until early November.

toward the northeast and splinters into complex branches. In the region of complex faulting there are some very large vertical and left-lateral horizontal offsets. It has been verified that this fault is related to the Chi-Chi earthquake (Central Geological Survey, 1999; Ma, et al., 1999). The distances between the LY station and the epicenters of the Chi-Chi earthquake and the Chia-Yi earthquake are about 50 kilometers and 100 kilometers, respectively. The differences in geomagnetic total intensity between the LY station and the reference station, the LP station, between mid-August and November 1999 were calculated and plotted as shown in Fig. 3. This figure revealed that the differences fluctuated significantly. The largest amplitude reached up to 200 nTs. These signals of disturbance were observed before the ChiChi earthquake and continued thereafter. Their amplitudes gradually weakened, and disturbance levels decreased to that of a quiet period almost right after the M6.2 Chia-Yi earthquake that occurred near the southern end of the Chelungpu fault (as shown in Fig. 1) on 22 October 1999. We believe these anomalous phenomena and their associated amplitudes are clearly related to the two earthquakes.

We also plotted the differences of geomagnetic data between the Tsengwen station (TW) and the LP station between late-September and November 1999 in Fig. 4. The TW station is located near the southern end of the Chelungpu fault, and is about 75 kilometers from the epicenter of the Chi-Chi earthquake and 30 kilometers from the Chia-Yi earthquake. Signals of disturbance were also revealed there. The amplitudes of disturbances were up to $100 \mathrm{nTs}$ which was smaller than that shown at the LY station. The signals of geomagnetic disturbance continued to early November.

We also examined the data observed at other stations. No geomagnetic fluctuation had been observed before or after either the Chi-Chi earthquake or the Chia-Yi earthquake. This may be due to the fact that those stations are far away from the epicenters and the subsequent severe surface ruptures. Thus, we believe that the geomagnetic fluctuations revealed at stations LY and TW are apparently related to the two earthquakes since the two stations are located close to the epicenters of the two earthquakes and to the Chelungpu fault. 
Table 1. Locations of all geomagnetic stations and their status.

\begin{tabular}{llll}
\hline \multicolumn{1}{c}{ station } & latitude & longitude & \multicolumn{1}{c}{ status } \\
\hline Taipei (TP) & 25.1290 & 121.5896 & new station \\
Lunping (LP) & 25.0000 & 121.1667 & abandoned station \\
Neicheng (NC) & 24.7181 & 121.6681 & instruments renovated \\
Yeheng (YH) & 24.6710 & 121.3671 & new station \\
Liyutan (LY) & 24.3467 & 120.7675 & instruments renovated \\
Hualien (HL) & 24.0678 & 121.6006 & instruments renovated \\
Shuanlung (SL) & 23.7902 & 120.9441 & new station \\
Yuli (YL) & 23.3506 & 121.2856 & instruments renovated \\
Tsengwen (TW) & 23.2514 & 120.5167 & instruments renovated \\
Taitung (TT) & 22.8019 & 121.0519 & instruments renovated \\
Pingtung (PT) & 22.7035 & 120.6496 & new station \\
Hengchun (HC) & 21.9350 & 120.8008 & instruments renovated \\
Kinmen (KM) & 24.4471 & 118.4164 & new reference station \\
\hline
\end{tabular}

Freund (2000) shows that positive holes can be activated in the crust by microfractures during the dilatancy phase (Bolt, 1999). Depending on where in the stressed rock volume the charge carriers are activated, they will form rapidly moving or fluctuating charge clouds that can account for earthquakerelated electric and magnetic signals. The decreasing senses of geomagnetic anomalies recorded at stations LY and TW indicate that underground flows of electric charge and/or fluid are highly anisotropic (Lonre et al., 1999). Although we do not yet have a complete understanding of the mechanisms for the nature of the geomagnetic fluctuations, this newly amended body of evidence concerning geomagnetic fluctuations provides us with a direction for further research in earthquake prediction. We are thus rapidly increasing the number of geomagnetic stations throughout Taiwan to integrate other results obtained from a variety of earthquake precursor studies, such as seismological observations, vertical changes in ground surface by INSAR, and the ionosphere and magnetosphere network and achieve the goal of mitigating earthquake hazards. In the new geomagnetic field observation network, we have renovated the seven existing geomagnetic observation stations, including those at Liyutan, Tsengwen, Hengchun, Taitung, Yuli, Hualien, Neicheng; and have established five new stations (Fig. 1 and Table 1). The geomagnetic observation station on Kinmen Island will be a new reference station in the geomagnetic network. The instruments installed in the new observation stations will have a higher resolution and sampling rate. The accuracy of the instruments will be $0.1 \mathrm{nT}$, the sampling rate will be 1 minute, and apart from being stored in the hard disks of the observation instruments, the geomagnetic data recorded will be relayed back to the National Central University Data center by way of telephone lines daily.

\section{Conclusion}

Geomagnetic fluctuations were clearly observed at the Liyutan station (LY), which is located about $8 \mathrm{~km}$ away from the northern end of the Chelungpu fault, both prior to and following the Chi-Chi Taiwan earthquake on September 21, 1999. The fluctuations at the station stopped after the Chia-Yi earthquake occurred on October 22. It has been verified that the Chi-Chi earthquake was associated with the Chelungpu fault, while the epicenter of Chia-Yi earthquake is about $50 \mathrm{~km}$ away from that of the Chi-Chi earthquake. Thus, these observations lead us to believe that these anomalous phenomena are connected to the process of accumulation and releases of crustal stress, and the subsequent severe surface ruptures. Geomagnetic fluctuations were also found at the TW station, located near the southern end of the Chelungpu fault. The fluctuations are also believed to be related to the Chi-Chi and Chia-Yi earthquakes. It may be concluded that the geomagnetic fluctuations due to the ChiChi and the Chia-Yi Taiwan earthquakes in 1999 had been observed. Although we do not clearly understand the mechanisms for the nature of the geomagnetic fluctuations at this moment, those observations shed new light and encourage us to conduct further studies of these questions.

Acknowledgments. The authors wish to express their appreciation to the Central Weather Bureau for providing earthquake data. This study was sponsored by the National Science Council and the Institute of Earth Sciences, Academia Sinica (Taiwan). This research was partially supported by the Ministry of Education Grant 91-NFA07-7-4, the iSTEP project, to the National Central University.

\section{References}

Akinaga, Y., M. Hayakawa, J. Y. Liu, K. Yumoto, and K. Hattori, A precursory ULF signature for Chi-Chi earthquake in Taiwan, Natural Hazards and Earth System Sciences, 1, 33-36, 2001.

Bolt, B. A., Earthquake, W. H. Freeman and Company, New York, ed. 4, 1999.

Central Geological Survey (of Taiwan), Geological survey report for the 921 earthquake, 315 pp., Central Geol. Surv. MOEA, ROC, 1999.

Chang, C. H., Y. M. Wu, T. C. Shin, and C. Y. Wang, Relocation of the 1999 Chi-Chi earthquake in Taiwan, TAO, 11, 581-590, 2000.

Fraser-Smith, A. C., A. Bernardi, P. R. McGill, M. E. Ladd, R. A. Helliwell, and O. G. Villard, Low-frequency magnetic field measurements near the epicenter of the Ms 7.1 Loma Prieta earthquake, Geophys. Res. Lett., 17, 1465-1468, 1990.

Freund, F., Time-resolved study of charge generation and propagation in igneous rocks, J. Geophys. Res., 105, 11001-11019, 2000.

Hayakawa, M., R. Kawate, O. A. Molchanov, and K. Yumoto, Result of ultra-low-frequency magnetic field measurements during the Guam earthquake of 8 August 1993, Geophys. Res. Lett., 23, 241-244, 1996.

Honkura, Y., Some results from measurements of the geomagnetic field and the electrical resistivity in the Izu-Tokai region, Japan, in Practical Approaches to Earthquake Prediction and Warning, edited by Kisslinger 
and Rikitake 365-378, 1985.

Lonre, B., F. Perrier, and J. P. Avouac, Streaming potential measurements 2. Relationship between electrical and hydraulic flow patterns from rock samples during deformation, J. Geophys. Res., 104, 17879-17896, 1999.

Ma, K. F., C. T. Lee, and Y. B. Tsai, The Chi-Chi, Taiwan earthquake: large surface displacements on an inland thrust fault, EOS, 80, 605, 1999.

Noritomi, K., Geoelectric and geomagnetic observations and phenomena associated with earthquake in China, Proc. on the Chinese earthquake prediction by the 1977 delegation of the Seismological Society of Japan, Seismol. Soc. Japan, 57-87, 1978.

Oike, K., Precursors and predictions of large earthquakes in China, Proc. on the Chinese earthquake prediction by the 1977 delegation of the Seismological Society of Japan, Seismol. Soc. Japan, 57-87, 1978. (in Japanese with English abstract)

Smith, B. E. and M. J. S. Johnston, A tectonomagnetic effect observed before a magnitude 5.2 earthquake near Hollister California, J. Geophys. Res., 81, 3556-3560, 1976.
Tsai, Y. B., T. L. Teng, Y. H. Yeh, S. B. Yu, K. K. Liu, and J. H. Wang, Status of earthquake prediction research in Taiwan, ROC, Bull. Inst. Earth Sciences, Academia Sinica, 3, 1-25, 1983.

Yamazaki, Y. and T. Rikitake, Local anomalous changes in the geomagnetic field at Matsushiro, Bull. Earthq. Res. Inst., Univ. Tokyo, 48, 637-643, 1970.

Yeh, Y. H., Y. B. Tsai, and T. L. Teng, Investigations of geomagnetic total intensity in Taiwan from 1979 to 1981, Bull. Inst. Earth Sciences, Academia Sinica, 1, 157-188, 1981.

Zhu, F. M., Prediction, warning, and disaster prevention to the Haicheng earthquake of magnitude 7.3, Proc. Lectures by the Seismological Delegation of the People's Republic of China, Seismol. Soc. Japan Special Publication, 15-26, 1976. (in Japanese)

H.-Y. Yen (e-mail: yenhy@earth.sinica.edu.tw), C.-H. Chen, Y.-H. Yeh, J.-Y. Liu, C.-R. Lin, and Y.-B. Tsai 